\title{
Mechanical and microstructural behaviour of wear resistant coatings on cast iron lathe machine beds and slides
}

\author{
H. Vasudev ${ }^{1 *}$, L. Thakur ${ }^{2}$, H. Singh ${ }^{3}$, A. Bansal ${ }^{1}$ \\ ${ }^{1}$ Department of Mechanical Engineering, I. K. Gujral Punjab Technical University, Kapurthala-144603, India \\ ${ }^{2}$ Department of Mechanical Engineering, National Institute of Technology, Kurukshetra-136119, India \\ ${ }^{3}$ Department of Mechanical Engineering, Guru Nanak Dev Engineering College, Ludhiana-141001, India
}

Received 16 February 2017, received in revised form 15 December 2017, accepted 16 January 2018

\begin{abstract}
The beds of the lathe and slides are subjected to abrasive and fatigue wear, which significantly affects their working life. The objective of this study is to enhance the useful life of the beds and slides. Detonation gun (D-Gun) sprayed WC-Co-Cr and $\mathrm{Al}_{2} \mathrm{O}_{3}+40 \mathrm{TiO}_{2}$ coatings on cast iron imitating lathe machine beds and slides with bare metal are analysed. The wear tests were performed on pin-on-disc apparatus using ASTM G99 standard for the uncoated and coated samples of cast iron. Coatings have been characterized by X-ray diffraction (XRD) and scanning electron microscopy (SEM) analysis. The results of coating characterization, experimental wear data generated, SEM micrographs along with energy dispersive spectroscopy (EDS) of the worn samples were used to analyse the wear behaviour of coated and uncoated cast irons. The results show that WC-Co-Cr and $\mathrm{Al}_{2} \mathrm{O}_{3}+40 \mathrm{TiO}_{2}$ coatings have been successfully deposited on cast iron by detonation gun spray process. The coated material has shown significantly less wear loss as compared to the uncoated material. The cumulative weight loss for detonation sprayed coatings increases with increase in load. The WC-Co-Cr coating has undergone minimum wear. Thus WC-Co-Cr coating deposited on cast iron has shown minimum wear as compared to $\mathrm{Al}_{2} \mathrm{O}_{3}+40 \mathrm{TiO}_{2}$ coated and uncoated cast iron.
\end{abstract}

K e y w or d s: thermal spray coatings, tungsten carbide cobalt chromium (WC-Co-Cr), aluminium oxide + titanium oxide $\left(\mathrm{Al}_{2} \mathrm{O}_{3}+40 \mathrm{TiO}_{2}\right)$, wear resistance

\section{Introduction}

Engineering components used in machinery function under various conditions in aggressive environments. Engineering environments are normally complex, combining loading leads to physical degradation of the surface of the component [1]. Surface wear damage is a phenomenon which affects how a component lasts in service. Wear problem in lathe beds and slides made of cast iron has been selected as a case study in present work, where abrasive and adhesive wear of the surface takes place due to the abrasive action [2-4]. Due to abrasive wear, the lathe beds and slides made of cast iron require frequent repair and replacement; it decreases their average useful life, which ultimately results in economic loss. To reduce the problem, it has been decided to use surface coatings on their surfaces.
Although many studies have been done related to the wear resistance of coatings deposited by plasma spray (PS) and high-velocity oxy-fuel methods, there is limited study available with the use of detonation gun spray (D-Gun) coating method to improve the wear resistance [5-7].

The substrate selected is cast iron which is commercially used for making beds and slides for lathe machines and other machine parts such as milling machine, boring machine, Plano Miller machine, etc. As it is widely used on a commercial basis in every industry, so it is selected. According to applicability and requirement among various carbides, tungsten carbide and chromium carbide are most preferred $[1$, 8-11]. As the machine bed and slides are mainly subjected to abrasive wear, the tungsten carbide cobalt chromium (WC-Co-Cr), aluminium oxide + titanium

*Corresponding author: e-mail address: hiteshvasudev@yahoo.in 
Table 1. Detonation gun (D-Gun) spray parameters for $\mathrm{Al}_{2} \mathrm{O}_{3}+40 \mathrm{TiO}_{2}$ and WC-Co-Cr coatings

\begin{tabular}{lcc}
\hline & \multicolumn{2}{c}{ Coatings } \\
\cline { 2 - 3 } Parameters & WC-Co-Cr & $\mathrm{Al}_{2} \mathrm{O}_{3}+40 \mathrm{TiO}_{2}$ \\
\hline Pressure of fuel gas (Oxygen) in bar & 2 & 2 \\
Pressure of fuel gas (Acetylene) in bar & 1.5 & 3.5 \\
Pressure carrier gas (Nitrogen) in bar & 3 & 3200 \\
Flow rate of fuel gas (Oxygen) in LPM & 2970 & 2320 \\
Flow rate of fuel gas (Acetylene) in LPM & 2400 & 960 \\
Flow rate of carrier gas (Nitrogen) in LPM & 960 & 165 \\
Stand-off distance (mm) & 165 & 110 \\
Substrate temperature ( $\left.{ }^{\circ} \mathrm{C}\right)$ & 110 & $100-150$ \\
Coating thickness (microns) & $100-150$ & \\
\hline
\end{tabular}

oxide $\left(\mathrm{Al}_{2} \mathrm{O}_{3}+40 \mathrm{TiO}_{2}\right)$ were selected as the coating materials on cast iron substrates because of their good wear resistance characteristics. In this study, the WC-Co-Cr and $\mathrm{Al}_{2} \mathrm{O}_{3}+40 \mathrm{TiO}_{2}$ were deposited by D-Gun technique. Detonation gun spray (D-Gun) process was selected as coating technique because it minimizes decomposition of the carbide phase due to lower heat enthalpy and shorter duration involved in the coating process. In thermal spray coatings, higher particle velocity during deposition provides several advantages such as lower porosity, higher bond strength and hardness $[1,12-16]$.

\section{Experimental material and procedure}

The cylindrical pins of circular cross-section dimensions, $5 \mathrm{~mm}$ diameter and length $30 \mathrm{~mm}$ have been made. A total of 9 pins were prepared. The pins were prepared on lathe machine, and their end faces (to be coated) were ground on the cylindrical grinding machine. Grinding was done to polish the end faces that the coating can be easily deposited. Grinding was followed by polishing with 110, 210, 310 and 410 grades polishing papers.

Powders used for coating process are as follows:

1. Aluminium oxide + titanium oxide $\left(\mathrm{Al}_{2} \mathrm{O}_{3}+\right.$ $\left.40 \mathrm{TiO}_{2}\right)$ : Aluminium oxide + titanium oxide powder was sprayed using the detonation spray process. It produces coatings, which are very hard, dense and excellently bonded. Aluminium oxide and titanium oxide coating is recommended for resistance to wear by fretting, abrasive particles oxidation and applicability in sliding conditions due to their high surface finish properties. The powder was supplied by H C Starck, Germany under the product code Amperit 584. The powder is agglomerated and sintered having a particle size of 10-45 microns.

2. Tungsten Carbide Cobalt Chromium (WC-12Co$-5 \mathrm{Cr}$ ): Tungsten carbide cobalt chromium powder, when sprayed using the detonation spray process, produces coatings, which exhibit excellent abrasive wear resistance under dynamic loading. In addition, higher particle velocity during deposition provides several advantages such as lower porosity, higher bond strength and hardness. It also has excellent corrosion resistance in the acidic environment.

The powder is supplied by H C Starck, Germany under the product code Amperit 556 and the composition of this powder given by supplier is $5-6 \mathrm{C}, 9$ 12.5Co, 0.8 Fe Max, 4-5Cr and $\mathrm{W}$ balance. The powder is agglomerated and sintered having a particle size of 15-45 microns. The various parameters adopted for performing the coatings are illustrated in Table 1.

The uncoated, as well as coated specimens, were prepared for sliding wear studies. The pins were polished with emery paper, and both disc and the pin were cleaned and dried before carrying out the test. The pin was loaded against the disc through a dead weight loading system. The wear tests for coated as well as uncoated specimens were conducted under three normal loads of 30,40 and $50 \mathrm{~N}$ and a fixed sliding velocity of $1 \mathrm{~ms}^{-1}$. The track radii for the pins were kept at $80 \mathrm{~mm}$. The loading system is equipped with a variable speed motor, and the speed can be changed at any time during the tests. The speed of rotation of the disc $(239 \mathrm{rpm})$ for all the cases was adjusted to keep the linear sliding velocity at a constant value of $1 \mathrm{~ms}^{-1}$. A variation of $\pm 5 \mathrm{rpm}$ was observed in the rpm of the disc. Wear tests have been carried out for a total sliding distance of $5400 \mathrm{~m}$ (6 cycles of 5, 5, 10, 10, 20 and $40 \mathrm{~min}$ duration) so that only top coated surface was exposed for each detonation sprayed specimen. The tangential force was monitored continuously during the wear tests. Weight loss of pins was measured after each cycle to determine the wear loss. The pin was removed from the holder after each run, cooled to room temperature, brushed lightly to remove loose wear debris, weighed and fixed again in the same position in the holder so that the orientation of the sliding surface remained unchanged. All weight measurements were carried out on a $0.1 \mathrm{mg}$ precision balance. 

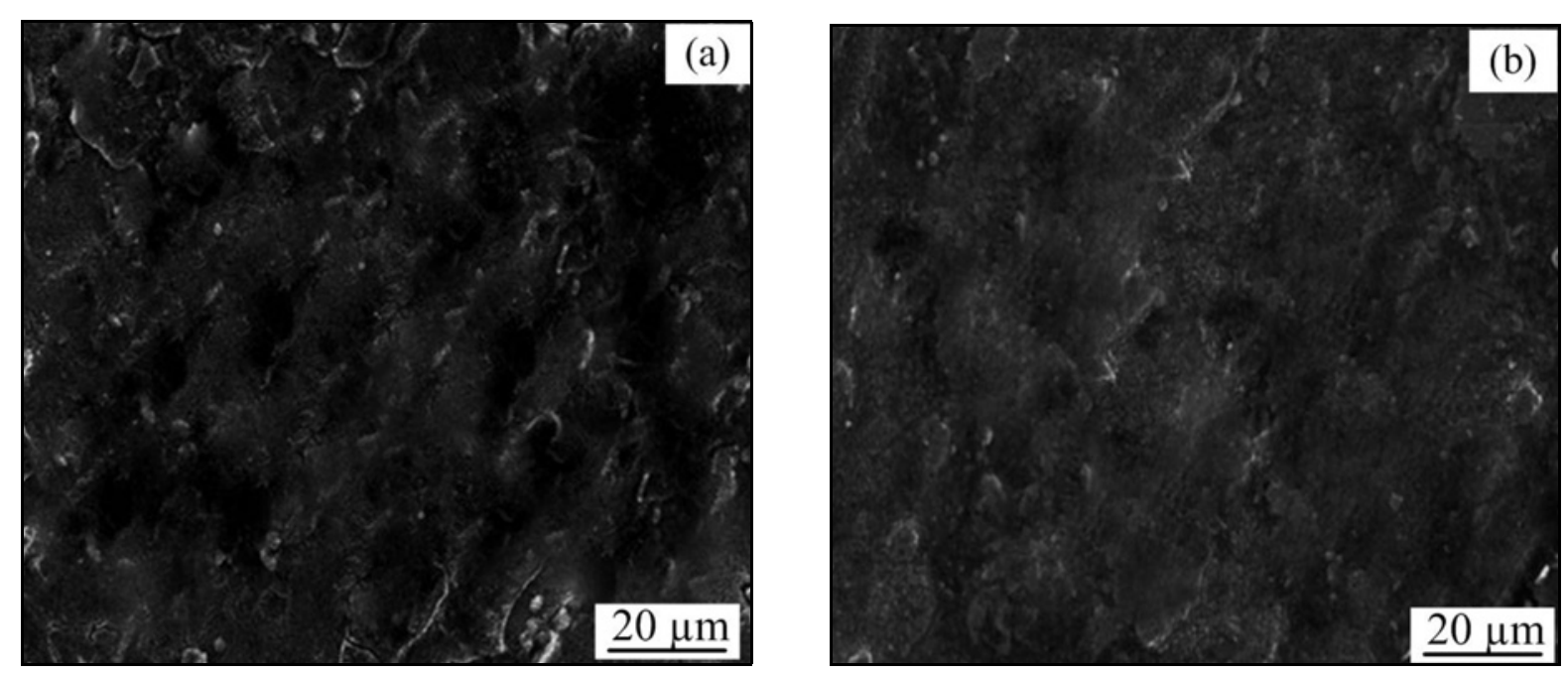

Fig. 1. Scanning electron micrograph illustrates the surface macrographs of D-Gun sprayed as-coated specimens: (a) $\mathrm{Al}_{2} \mathrm{O}_{3}$ $+40 \mathrm{TiO}_{2}$ and (b) WC-Co-Cr.
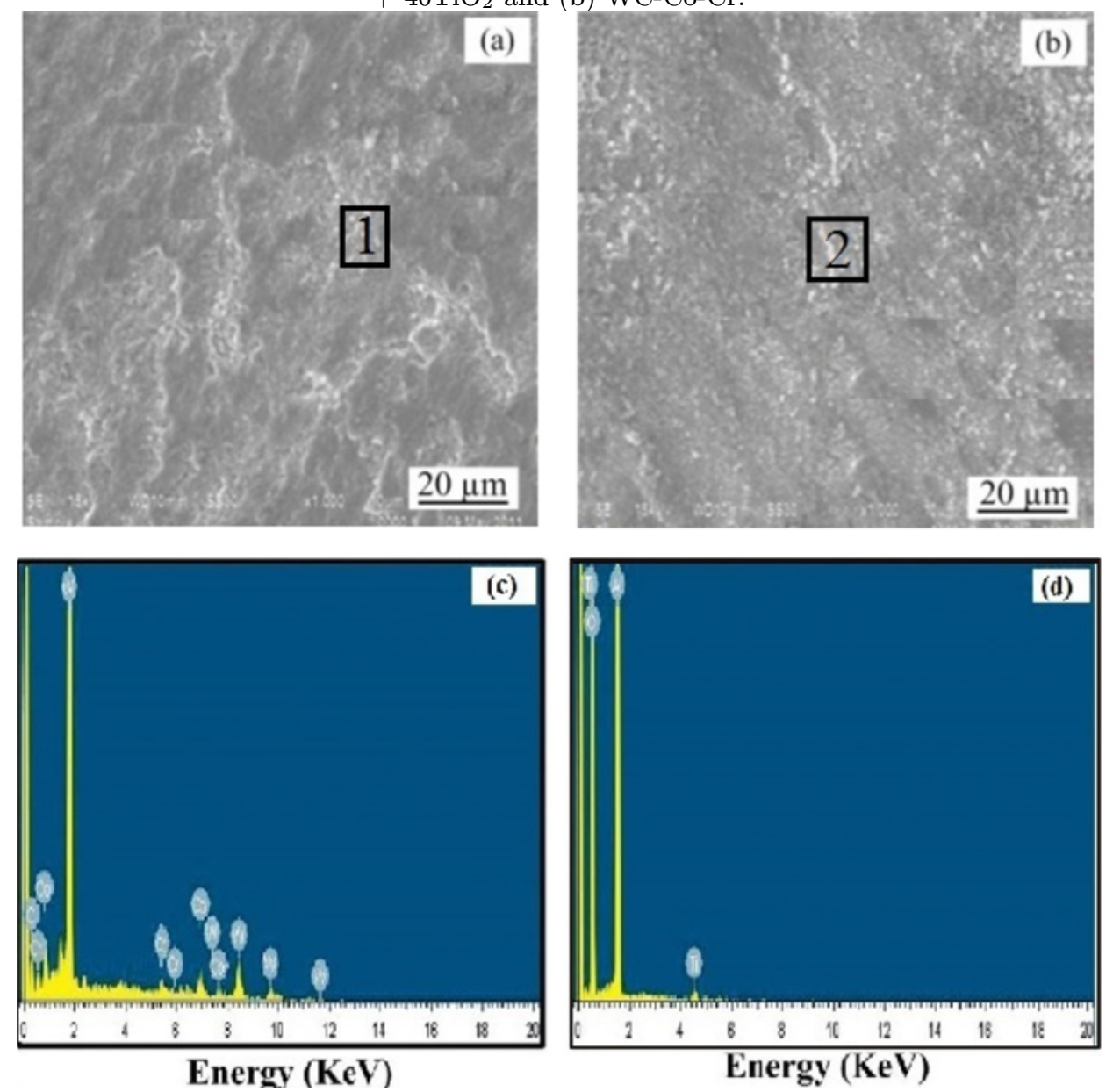

Fig. 2. SEM micrograph illustrates the surface morphology of as-coated specimens of (a) WC-Co-Cr and (b) $\mathrm{Al}_{2} \mathrm{O}_{3}+$ $40 \mathrm{TiO}_{2}$ coatings, (c, d) EDS spectra corresponding to location 1 and 2 of Fig. (a) and (b), respectively.

XRD analysis was carried out for the as-coated specimens to identify various phases present on their surfaces. The X-ray diffraction patterns were obtained by X'Pert PRO, Panalytical Advance Diffractometer (Netherlands) with $\mathrm{Cu} \mathrm{K} \alpha$ radiation and nickel fil- ter at $40 \mathrm{~mA}$ under a voltage of $45 \mathrm{kV}$ available at XRD lab, Indian Institute of Technology, Ropar (India).

The surface morphologies of the as-sprayed specimens were studied with the help of a field emis- 

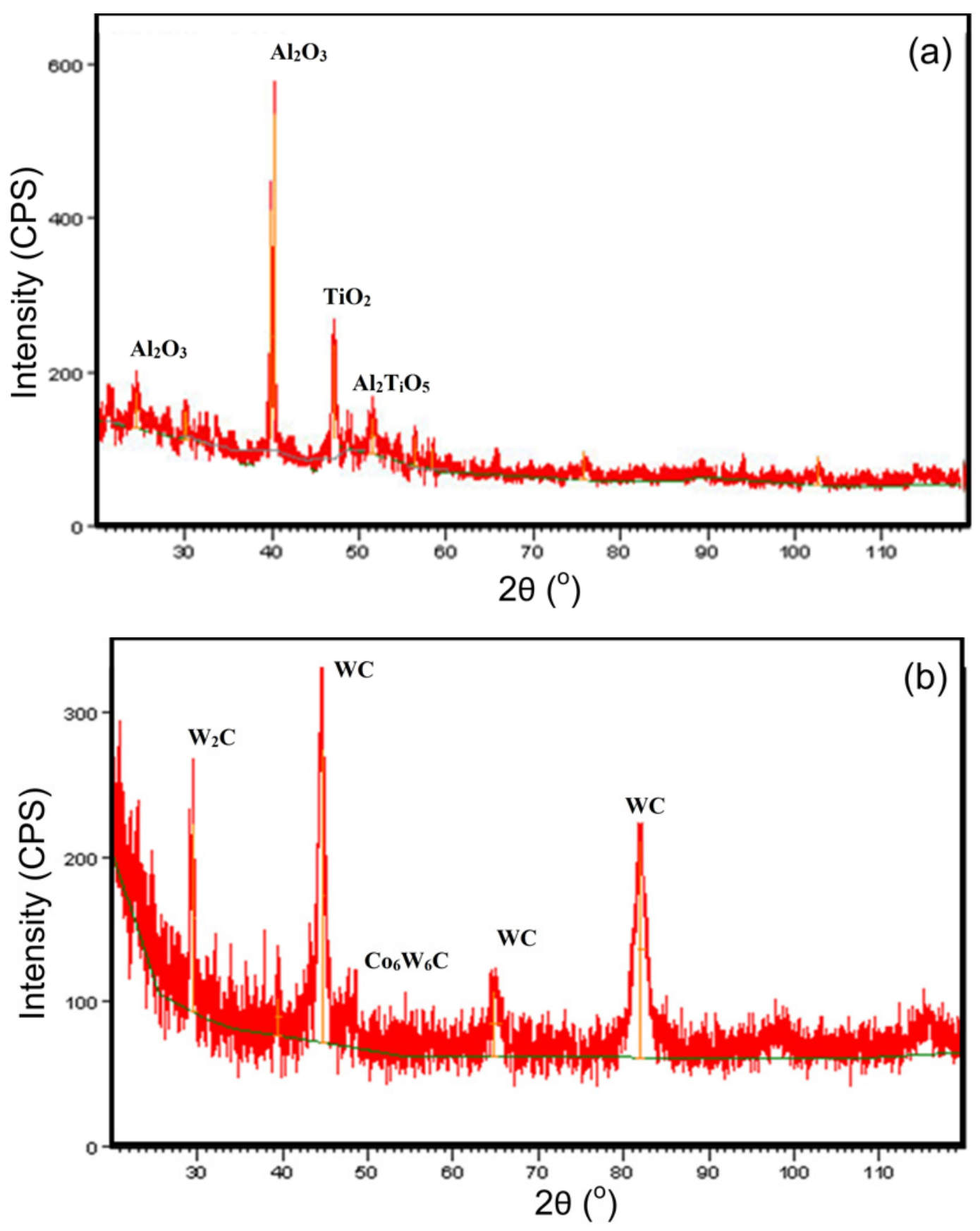

Fig. 3. X-ray diffraction pattern of as-coated (a) $\mathrm{Al}_{2} \mathrm{O}_{3}+40 \mathrm{TiO}_{2}$ and (b) WC-Co-Cr coatings on cast iron.

sion scanning electron microscope (JSM 6610LV, JEOL) fitted with energy dispersive X-ray spectroscopy (EDS) genesis software attachment available at SEM lab, Indian Institute of Technology, Ropar (India), with an aim to identify inclusions, un-melted, partially melted particles and pores in the as-sprayed coatings. The EDS genesis software indicates the elemental compositions (wt.\%) present at point/area of interest. Although the composition corresponds to selected points on the as-sprayed surfaces, it is useful to understand the formation of desired compositions in the coatings.

\section{Experimental results}

In the characterization of coatings with visual inspection, it is observed from the scanning electron microscopy (SEM) that the $\mathrm{Al}_{2} \mathrm{O}_{3}+40 \mathrm{TiO}_{2}$ coating has the deep blackish grey appearance shown in Fig. 1a whereas WC-Co-Cr coating appears as dull medium grey as shown in Fig. 1b. Further, no cracks were observed on the coating surface in the SEM micrograph during a visual examination.

Microstructural analysis of coatings includes SEM micrographs and energy dispersive spectra (EDS) with 

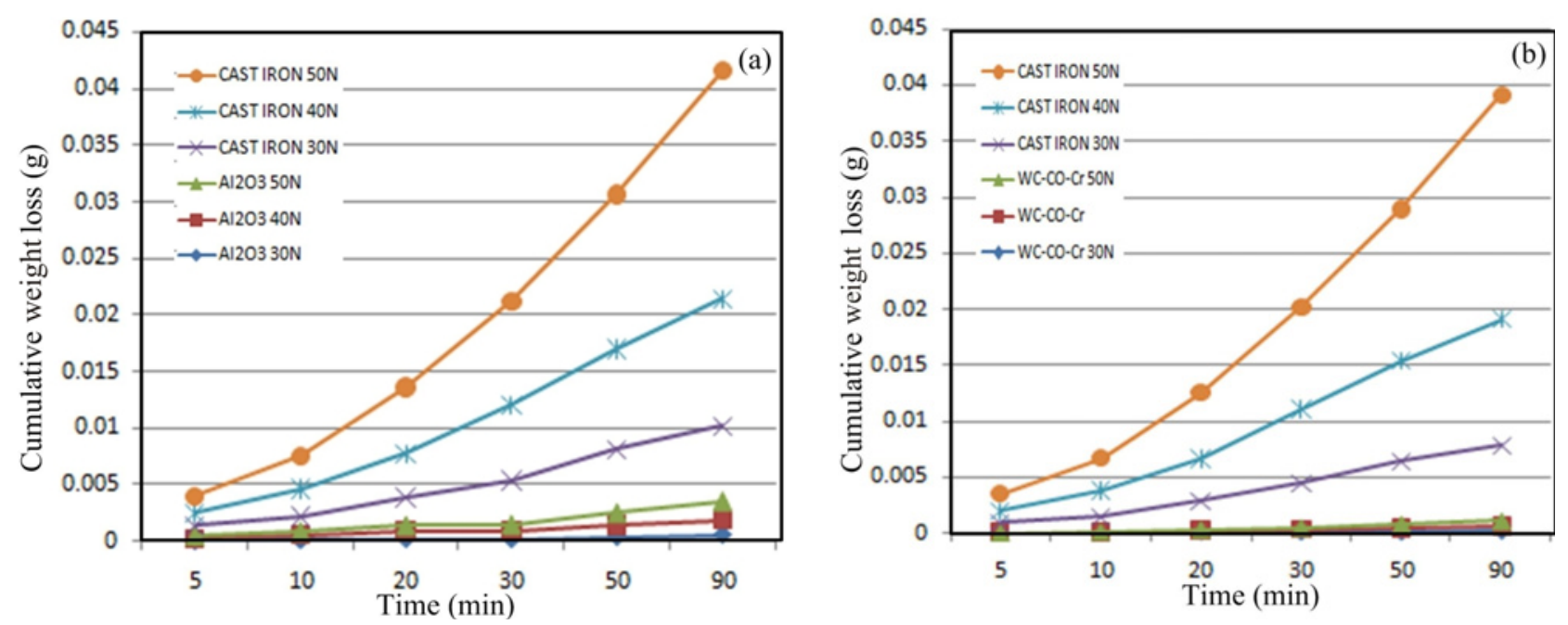

Fig. 4. Cumulative weight loss with time for (a) $\mathrm{Al}_{2} \mathrm{O}_{3}+40 \mathrm{TiO}_{2}$ and (b) WC-Co-Cr coatings v/s cast iron substrate.

the elemental composition of detonation sprayed WC$\mathrm{Co}-\mathrm{Cr}$ and $\mathrm{Al}_{2} \mathrm{O}_{3}+40 \mathrm{TiO}_{2}$ coatings on cast iron shown in Figs. 2a and 2b, respectively. In general, micrographic features indicate that the coatings are uniform, homogeneous and free from surface cracks. The WC-Co-Cr coating has small size splats whereas the splats are coarse for $\mathrm{Al}_{2} \mathrm{O}_{3}+40 \mathrm{TiO}_{2}$. The EDS analysis of the coatings was done at selected areas of interest as shown in Figs. 2c and 2d.

The elemental composition of $\mathrm{Al}_{2} \mathrm{O}_{3}+40 \mathrm{TiO}_{2}$ coating corresponding to point 2 in Fig. 2 d confirms the presence of desired coating elements like $\mathrm{Al}, \mathrm{Ti}$ and oxides etc., but a small amount of oxygen exceeded from the expected values indicates the formation of oxides during detonation spray process. The presence of $\mathrm{O}$ on the top surface indicates the possibility of oxides formation and decarburization of carbide particles. The point 1 in Fig. 2c for WC-Co-Cr coating indicates the presence of desired elements as W, C, Co. The presence of C element (possibly available from the substrate material) on the top surface indicates the possibility of carbide formation with $\mathrm{W}$.

The X-ray diffractograms for detonation sprayed $\mathrm{Al}_{2} \mathrm{O}_{3}+40 \mathrm{TiO}_{2}$ and WC-Co-Cr coatings on cast iron are shown in Fig. 3. It is evident that the as-sprayed $\mathrm{Al}_{2} \mathrm{O}_{3}+40 \mathrm{TiO}_{2}$ coating contains $\mathrm{Al}_{2} \mathrm{O}_{3}$ as a major phase and $\mathrm{TiO}_{2}$ as a minor phase. Some intermetallic $\left(\mathrm{Al}_{2} \mathrm{~T}_{1} \mathrm{O}_{5}\right)$ was also observed in the XRD spectrum (Fig. 3a). The phases obtained in XRD pattern of WC-Co-Cr coatings are $\mathrm{Co}_{6} \mathrm{~W}_{6} \mathrm{C}, \mathrm{W}_{2} \mathrm{C}$ and $\mathrm{WC}$ (Fig $3 \mathrm{~b}$ ). However, the major constituents found on coating are $\mathrm{W}$ and $\mathrm{C}$ in the XRD pattern (Fig. 3b).

The wear analysis of the specimens was carried out through the pin-on-disc test. Three samples of each coated specimens $\left(\mathrm{Al}_{2} \mathrm{O}_{3}+40 \mathrm{TiO}_{2}\right.$ and WC-Co-Cr coating on cast iron) were subjected to wear on a pinon-disc wear test rig at normal loads of 30,40 and $50 \mathrm{~N}$, respectively. Three samples of cast iron substrate

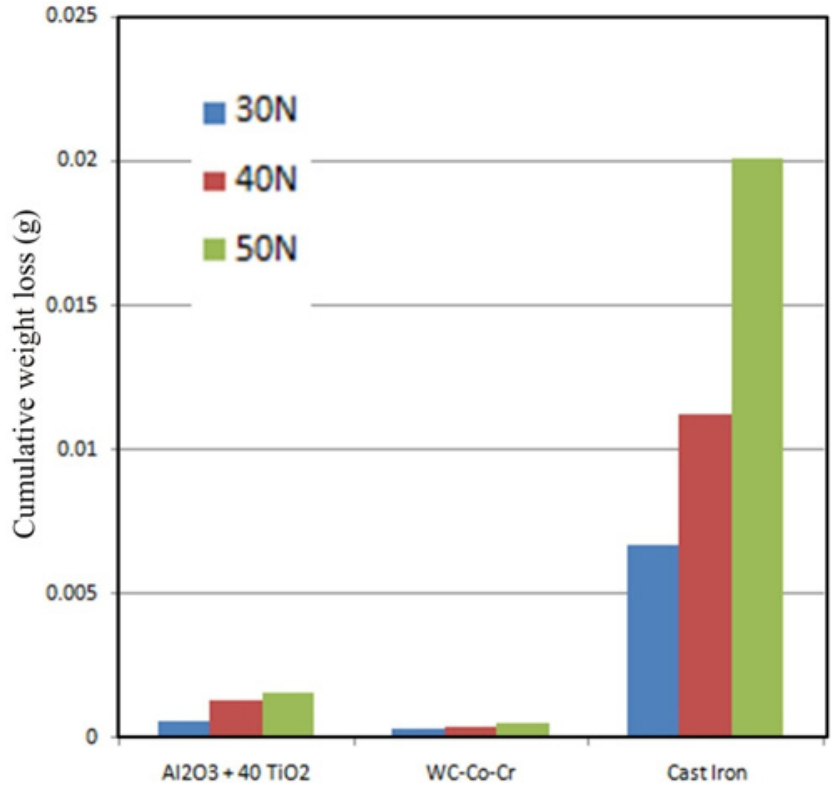

Fig. 5. Cumulative weight loss with time for $\mathrm{Al}_{2} \mathrm{O}_{3}+$ $40 \mathrm{TiO}_{2}$, WC-Co-Cr coatings and bare cast iron substrate.

were also subjected to wear on a pin-on-disc wear test rig at 30, 40 and $50 \mathrm{~N}$ the same loads. The cumulative volume loss $\mathrm{v} / \mathrm{s}$ time for each sample is plotted as shown in Fig. 4. The bar chart showing the cumulative weight loss (CWL) in one cycle (90 min) is also drawn for each coating substrate as shown in Fig. 5. It is observed from the results mentioned in Fig. 6 that the coatings $\mathrm{Al}_{2} \mathrm{O}_{3}+40 \mathrm{TiO}_{2}$ and $\mathrm{WC}-\mathrm{Co}-\mathrm{Cr}$ show better wear resistance as compared to cast iron substrate material. It is observed from Fig. $4 \mathrm{~b}$ the coating shows only a marginal increase in CWL with time. The corresponding CWL for $\mathrm{Al}_{2} \mathrm{O}_{3}+40 \mathrm{TiO}_{2}$ coating is almost negligible as compared to bare cast iron as shown in Fig. 4a. The wear rate of $\mathrm{WC}-\mathrm{Co}-\mathrm{Cr}$ is very little as 

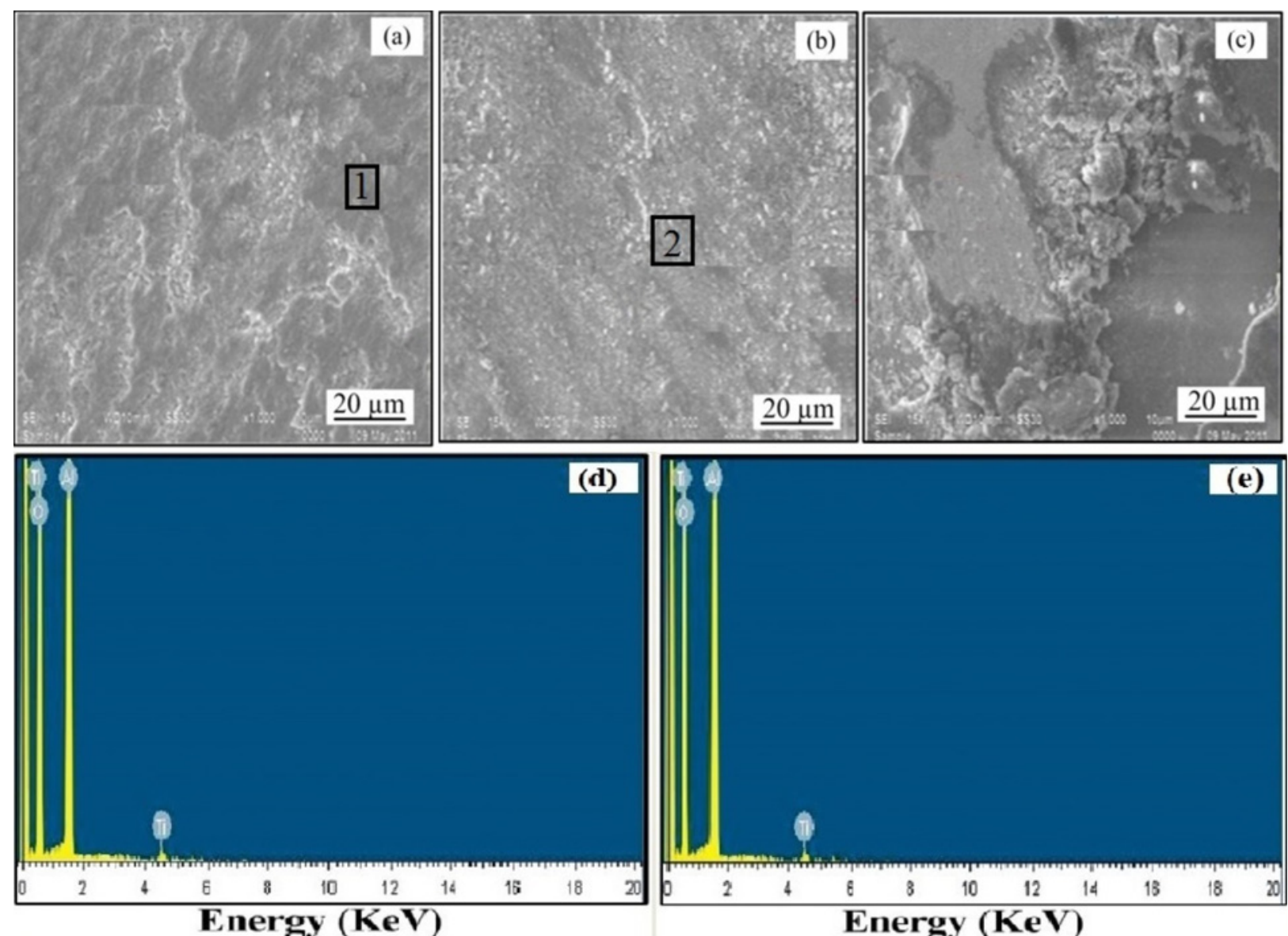

Fig. 6. SEM micrographs and EDS spectra of worn out samples for $\mathrm{Al}_{2} \mathrm{O}_{3}+40 \mathrm{TiO}_{2}$ at 30,40 and $50 \mathrm{~N}$.

compared to bare cast iron, which is shown by a flat curve between CWL and time in Fig. 5. The CWL for bare cast iron is comparatively high as compared to two coatings. It is also observed that with an increase in load, wear loss increases for $\mathrm{Al}_{2} \mathrm{O}_{3}+40 \mathrm{TiO}_{2}$ detonation sprayed coatings, but it has minimal effect on WC-Co-Cr coating as observed in Fig. 5. In case of uncoated cast iron substrate, material wear loss increases with increase in load as shown in Fig. 5.

The surface morphology and EDS analysis of the worn surfaces of $\mathrm{Al}_{2} \mathrm{O}_{3}+40 \mathrm{TiO}_{2}$, WC-Co-Cr and uncoated cast iron substrate at normal loads of 30,40 and $50 \mathrm{~N}$ are shown in Figs. 6, 7.

An elemental composition corresponding to points 1 and 2 in Figs. 6a,b for $\mathrm{Al}_{2} \mathrm{O}_{3}+40 \mathrm{TiO}_{2}$ coating confirms the wear resistance with the presence of $\mathrm{Al}$, $\mathrm{Ti}$ and oxygen thereby retaining the powder phase and similarly in Figs. 7a,b for WC-Co-Cr coatings the presence of $\mathrm{WC}$, Co and Cr elements confirms the retained phases of the coating. Figures $6 \mathrm{a}$ and $7 \mathrm{a}$ show that the area is slightly rich in elements which are present in the coating powders used like $\mathrm{Al}, \mathrm{WC}$, Co and $\mathrm{Ti}$, whereas their percentages are less indicated in the worn out areas. The elemental composition corresponding to points in Fig. $6 \mathrm{~b}$ shows that the grey area is rich in Fe as compared to Fig. 6a in case of $\mathrm{Al}_{2} \mathrm{O}_{3}$ $+40 \mathrm{TiO}_{2}$ coating and it may represent the deposition of wear debris as compared to the virgin coated areas with the increase in load and material worn out and shows another element instead of freshly coated surfaces, and this further shows that this coating is less wear resistant than WC-Co-Cr coating. The area is also found to be rich in $\mathrm{O}$ and $\mathrm{C}$, and hence it may be due to the presence of carbide and oxide Fe on the surface. The grey areas in the Figs. 6c, 7c and 8c show the worn out surface which significantly decreases in the amount of $\mathrm{Al}, \mathrm{WC}$, Co and $\mathrm{Ti}$ whereas the very high amount of Fe infers the worn out surface as it is the major constituent of the substrate.

\section{Discussion}

The comparison of wear loss for the coatings $\mathrm{Al}_{2} \mathrm{O}_{3}$ $+40 \mathrm{TiO}_{2}$ and $\mathrm{WC}-\mathrm{Co}-\mathrm{Cr}$ on cast iron at 30, 40 and $50 \mathrm{~N}$ is shown in Fig. 5. It is observed from the results that WC-Co-Cr is showing almost negligible cumulative weight loss (CWL) as compared to the uncoated substrate and $\mathrm{Al}_{2} \mathrm{O}_{3}+40 \mathrm{TiO}_{2}$. As compared to bare cast iron and $\mathrm{Al}_{2} \mathrm{O}_{3}+40 \mathrm{TiO}_{2}$, the WC-Co- 


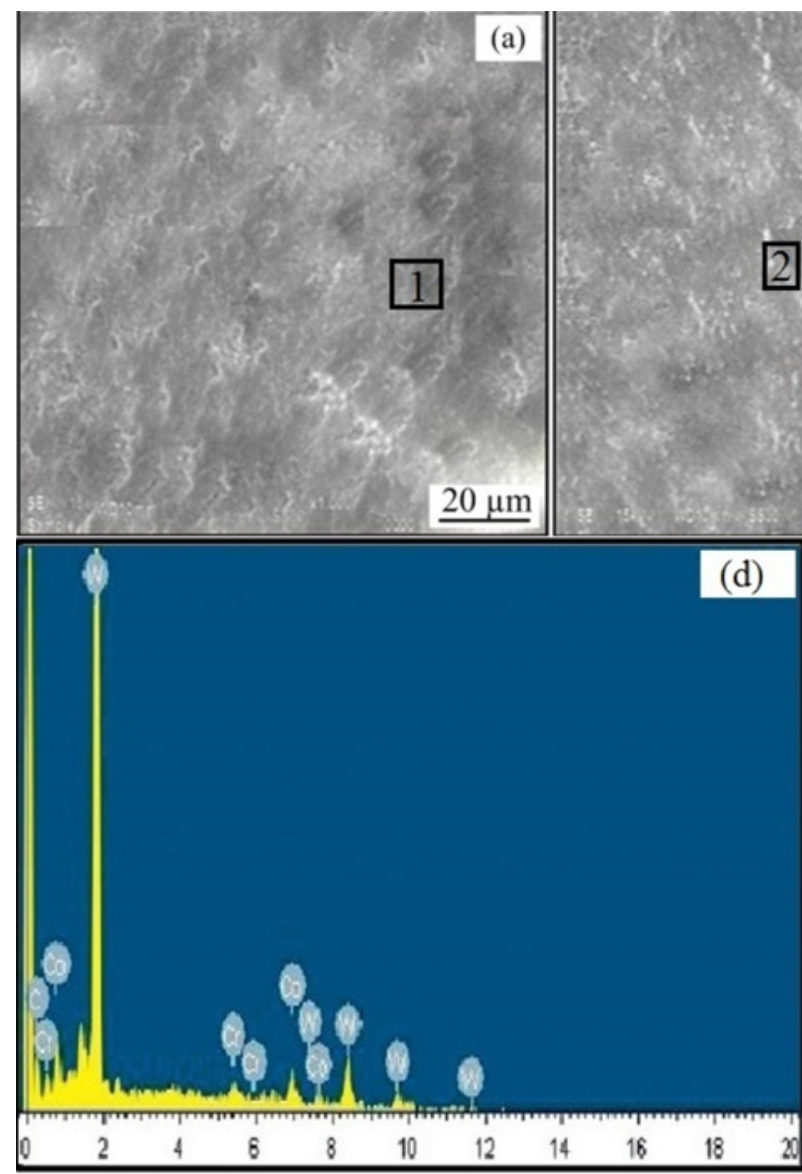

Energy ( $\mathrm{KeV})$
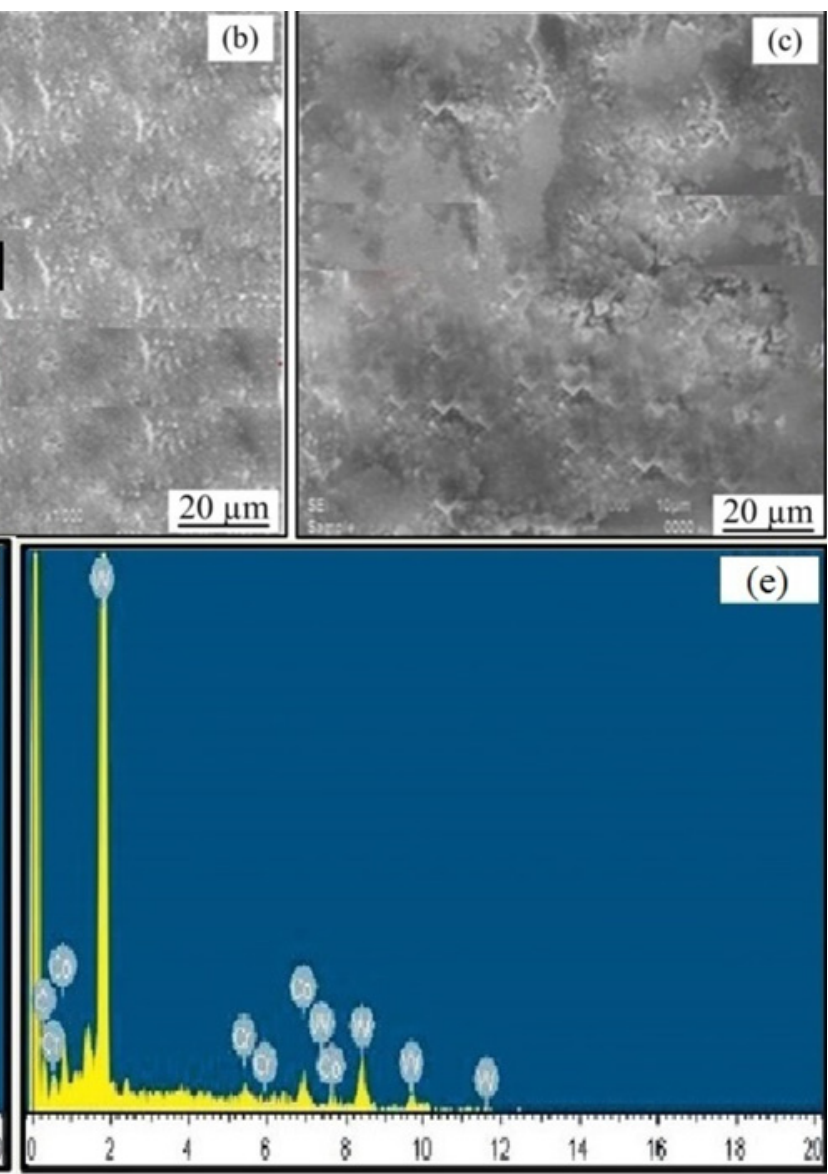

Energy $(\mathrm{KeV})$

Fig. 7. SEM micrographs and EDS spectra of worn out samples for WC-Co-Cr at 30, 40 and $50 \mathrm{~N}$.

-Cr shows almost equal wear at 30 and $40 \mathrm{~N}$ and shows the marginal difference in wear at $50 \mathrm{~N}$. Therefore performance in terms of wear resistance of detonation sprayed coatings on cast iron in their decreasing order can be given as WC-Co-Cr $>\mathrm{Al}_{2} \mathrm{O}_{3}+40 \mathrm{TiO}_{2}>$ cast iron. Moreover, the XRD results show the presence of $\mathrm{WC}$ as the major and primary phase along with $\mathrm{Co}_{6} \mathrm{~W}_{6} \mathrm{C}$ and $\mathrm{W}_{2} \mathrm{C}$ as the secondary phases, and it eventually indicates that $\mathrm{WC}$ grains are present in a single phase. $\mathrm{Co}_{6} \mathrm{~W}_{6} \mathrm{C}$ represents the combination of Co and $\mathrm{WC}$ to form a compound, and coating powder is decomposed which is represented by $\mathrm{W}_{2} \mathrm{C}$, and this leads to a successful coating with strong mechanical bonding as well. Furthermore, the SEM micrographs and EDS spectra of worn out samples $\mathrm{Al}_{2} \mathrm{O}_{3}+40 \mathrm{TiO}_{2}$ at different loadings show that with an increase in load on the coated substrates, the elements present in the coatings like Al, WC, Co and Ti provide the wear resistance shown in Figs. 6 and 7.

Other thermal coating techniques like high-velocity oxy-fuel and flame spraying have some issues like lower bond strength, decomposition of powder and a higher degree of porosities. However, these problems have been resolved with the use of detonation gun spray coating technique due to the high velocity of spraying process which further reduces porosity. In the WC-Co-Cr coating WC alone provides a shield against abrasive and fatigue wear. The addition of $\mathrm{Cr}$ to WC-Co holds up the decomposition of tungsten carbide and avoids the formation of metallic tungsten. The SEM images of WC-Co-Cr in Figs. 2a and 7a respectively indicate that there is a homogeneous splat geometry distribution of every element in the coating including $\mathrm{W}$ and $\mathrm{C}$ as major elements present there. Moreover, Figs. 2a and 7 also represent that the wt. percentage of $\mathrm{W}$ is more than two times the $\mathrm{C}$, which caused the formation of $\mathrm{W}_{2} \mathrm{C}$, and this is also indicated in the XRD pattern as well. The presence of $\mathrm{W}_{2} \mathrm{C}$ does not certainly indicate the decomposition of powder in spraying. However, the extent of the same is not significant. The decomposition of powder might have taken place due to overheating of some smaller sized particles in the coating process.

\section{Conclusions}

Based upon experimental results obtained in the 

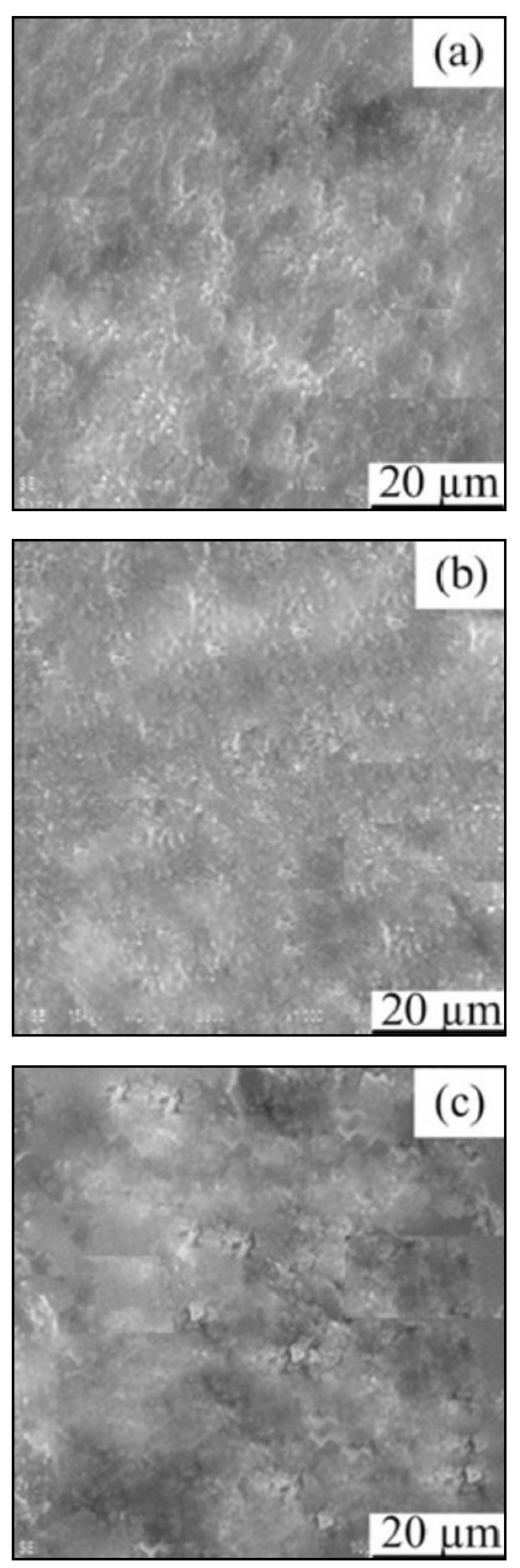

Fig. 8. SEM micrographs and EDS spectra of worn out samples of cast iron at 30,40 and $50 \mathrm{~N}$.

present work, the following conclusions have been drawn:

1. Detonation sprayed $\mathrm{Al}_{2} \mathrm{O}_{3}+40 \mathrm{TiO}_{2}$ and $\mathrm{WC}$ -Co-Cr coatings have successfully been deposited on cast iron without any sign of cracks and have good mechanical bonding with the substrate.

2. The XRD patterns show the major phase present on the surface of WC-Co-Cr coating is WC, and in the $\mathrm{Al}_{2} \mathrm{O}_{3}+40 \mathrm{TiO}_{2}$ coating, the major phases are $\mathrm{Al}_{2} \mathrm{O}_{3}$ and $\mathrm{TiO}_{2}$, which provides good performance in terms of wear resistance as compared to uncoated cast iron substrate.

3. The detonation sprayed $\mathrm{Al}_{2} \mathrm{O}_{3}+40 \mathrm{TiO}_{2}$ and WC-Co-Cr coated on cast iron specimens show significantly lower cumulative weight loss as compared to uncoated cast iron substrate.

4. Cumulative weight loss for detonation sprayed $\mathrm{Al}_{2} \mathrm{O}_{3}+40 \mathrm{TiO}_{2}$ and $\mathrm{WC}-\mathrm{Co}-\mathrm{Cr}$ coated as well as uncoated cast iron specimens increased with increase in load.

5. Cumulative weight loss for WC-Co-Cr coating was observed to be minimum in the present study.

6. The WC-Co-Cr coating has shown minimum $\mathrm{cu}-$ mulative weight loss among all the combinations. The wear resistance for coating-substrate combinations in their decreasing order (at 30, 40 and $50 \mathrm{~N}$ ) is WC-Co$-\mathrm{Cr}>\mathrm{Al}_{2} \mathrm{O}_{3}+40 \mathrm{TiO}_{2}>$ cast iron.

\section{References}

[1] Rajasekaran, B., Ganesha, S. R. S., Joshi, S.V., Sundararajan, G.: International Journal of Fatigue, 31, 2009, p. 791. doi:10.1016/i.ijfatigue.2008.03.003

[2] Sundararajan, G., Sen, D., Sivakumar, G.: Wear, 258, 2005, p. 377. doi:10.1016/j.wear.2004.03.022

[3] Singh Sidhu, H., Singh Sidhu, B. S., Prakash, S.: Journal of Materials Processing Technology, 171, 2006, p. 77. doi:10.1016/i.jmatprotec.2005.06.058

[4] Murthy, K. N. J., Venkataraman, B.: Surface \& Coatings Technology, 200, 2006, p. 2642. doi:10.1016/j.surfcoat.2004.10.136

[5] Murthy, K. N. J., Rao, S. D., Venkataraman, B.: Wear, 249, 2001, p. 592. doi:10.1016/S0043-1648(01)00682-2

[6] Miguel, J. M., Guilemany, J., Vizcaino, S.: Tribology International, 36, 2003, p. 181. doi:10.1016/S0301-679X(02)00144

[7] Rama, K. L., Sen, D., Srinivasa, R. D., Sundararajan, G.: Journal of Thermal Spray Technology, 12, 2003, p. 77. doi:10.1361/105996303770348528

[8] Rama, K. L., Sen, D., Srinivasarao, Y. V., Narasimharao, G., Sundararajan, G.: Journal of Materials Research, 366, 2002, p. 2514. doi:10.1557/JMR.2002.0366

[9] Mohanty, M. W., Smith, R., De Bonte, M. P., Celis, J., Lugscheider, E.: Wear, 198, 1996, p. 251. doi:10.1016/0043-1648(96)06983-9

[10] Kahraman, N., Gulenc, B.: Materials and Design, 23, 2002, p. 721. doi:10.1016/S0261-3069(02)00075-4

[11] Karoonboonyanan, S., Salokhe, M.V., Niranatlumpong, P.: Wear, 263, 2007, p. 604. doi:10.1016/j.wear.2006.12.072

[12] Singh, H., Grewal, M. S., Sekhon, H. S., Rao, R. G.: Journal of Engineering Tribology, 222, 2008, p. 601. doi:10.1243/13506501JET362

[13] Suk, M., Gillis, D. R., Singh, G. P.: IEEE Transactions on Magnetics, 35, 1999, p. 2352. $\underline{\text { doi: } 10.1109 / 20.800822}$ 
[14] Sahraoui, T. F., Enineche, E., Montavon, G., Coddet, C.: Journal of Materials and Design, 24, 2003, p. 309.

[15] Salokhe, V. M., Chuenpakaranant, W., Niyampa T.: Journal of Terramechanics, 36, 1999, p. 127. doi:10.1016/S0022-4898(99)00002-6
[16] Vasudev, H., Thakur, L., Bansal, A.: In: Proceedings of 4th International Conference on Production and Industrial Engineering. Jalandhar, National Institute of Technology 2016, p. 188. 